\title{
Severe fatigue due to valproate-induced hypothyroidism in a case of bipolar disorder
}

\author{
Tadashi Kanamori ${ }^{1,2},{\text { Masahiro Suzuki }{ }^{1 *}, \text { Yoshiyuki Kaneko }^{1}, \text { Kouju Yamada }^{1,2} \text {, Hideyuki Kubo }}^{1}$
}

and Makoto Uchiyama ${ }^{1,3}$

\begin{abstract}
Background: Valproate-induced hypothyroidism is a rare condition and has been considered asymptomatic. Here, we report a case of bipolar I disorder who developed symptomatic valproate-induced hypothyroidism.

Case presentation: A 44-year-old woman with bipolar I disorder complained of severe fatigue after starting valproate. She showed a hormonal pattern of central hypothyroidism. Thyroid autoantibodies were negative, and no pituitary abnormality was seen on magnetic resonance imaging. After stopping valproate, her severe fatigue rapidly improved with normalizing thyroid function.
\end{abstract}

Conclusions: Our case suggests that valproate-induced hypothyroidism should be considered when patients complain of excessive fatigue under treatment with valproate.

Keywords: Bipolar disorder, Hypothyroidism, Symptomatic, Valproate

\section{Background}

Valproate, which is recognized to be much safer than lithium, the archetypal mood stabilizer, in terms of effects on thyroid function, is widely used in the treatment of bipolar disorder [1]. However, previous reports have suggested that valproate can also cause hypothyroidism [2, 3]. Here, we report a case of bipolar disorder showing severe fatigue due to valproate-induced hypothyroidism.

\section{Case presentation}

A 44-year-old woman with bipolar disorder was referred to our outpatient clinic 2 months after her first manic episode. She developed bipolar disorder with depressive episodes when she was 42 years old. Her first depressive episode was ameliorated with 3 months' treatment with sertraline. She had no previous episodes of hypomania or mixed states, and no history of thyroid disease. When she

*Correspondence: suzuki.masahiro94@nihon-u.ac.jp

1 Department of Psychiatry, Nihon University School of Medicine, 30-1 Oyaguchi-Kamicho, Itabashi-ku, Tokyo 173-8610, Japan

Full list of author information is available at the end of the article presented at our clinic, she had been treated with quetiapine for 1 month, but still had elevated mood, irritability, and mood-congruent delusions. According to the Diagnostic and Statistical Manual of Mental Disorders, 5th edition, we diagnosed her as having bipolar I disorder, and added $200 \mathrm{mg}$ of valproate on $100 \mathrm{mg}$ of quetiapine. Valproate was later increased to $400 \mathrm{mg}$, after which, her manic symptoms ameliorated.

Despite her mood being well controlled, she developed severe fatigue 30 days after starting valproate. She had no depression-related symptoms other than fatigue, and no findings suggesting sedation with valproate such as somnolence or impaired attention. Her blood concentration of valproate was $24.2 \mu \mathrm{g} / \mathrm{mL}$, which was not at the toxic level (normal range $50-100 \mu \mathrm{g} / \mathrm{mL}$ ). She had never had a similar reaction to previously used psychotropics. A physical examination and laboratory test found no abnormalities except for low values of free thyroxine $0.50 \mathrm{ng} /$ $\mathrm{dL}$ (F-T4; normal range $0.8-1.5 \mathrm{ng} / \mathrm{dL}$ ) and free triiodothyronine $1.85 \mathrm{pg} / \mathrm{mL}$ (F-T3; normal range $2.0-3.8 \mathrm{pg} /$ $\mathrm{mL}$ ). Although F-T4 was decreased, thyroid-stimulating hormone $2.97 \mu \mathrm{U} / \mathrm{mL}$ (TSH; normal range $0.34-3.8 \mu \mathrm{U} /$ 
$\mathrm{mL}$ ) was within the normal range, suggesting central hypothyroidism. Since other fatigue-causing medical conditions and medications were ruled out by systematic evaluations, we considered that the severe fatigue was associated with hypothyroidism. Thyroid autoantibodies were negative, and gadolinium-enhanced magnetic resonance imaging of the pituitary gland showed no evidence of a pituitary lesion. Considering that her F-T4 levels progressively decreased with increasing doses of valproate (F-T4 $0.70 \mathrm{ng} / \mathrm{dL}$ under $200 \mathrm{mg}$ and F-T4 $0.50 \mathrm{ng} / \mathrm{dL}$ under $400 \mathrm{mg}$ ), we suspected that her hypothyroidism was caused by valproate. Therefore, we stopped valproate 33 days after its introduction. Her severe fatigue then improved, completely disappearing in about 20 days. A laboratory test 35 days after stopping valproate confirmed that her thyroid function had normalized (TSH $2.17 \mu \mathrm{U} / \mathrm{mL}$, F-T3 $2.99 \mathrm{pg} / \mathrm{mL}$, F-T4 $1.10 \mathrm{ng} / \mathrm{dL}$ ). For the next 12 months, she had no recurrence of mood episodes, hypothyroidism, or fatigue under maintenance treatment with risperidone and carbamazepine.

\section{Discussion}

In this case, severe fatigue was relieved by discontinuation of valproate with normalizing thyroid function. In addition, her severe fatigue and hypothyroidism were clearly exacerbated depending on the dose of valproate. Therefore, we determined that the use of valproate was associated with her hypothyroidism and severe fatigue. Furthermore, we assessed the causal relationship between the use of valproate and the observed reactions using the Adverse Drug Reaction Probability Scale developed in 1981 by Naranjo and coworkers (i.e., the Naranjo Scale) [4]. This scale has been widely used to assess causality for adverse drug reactions. The Naranjo Scale is composed of 10 questions that are answered as either "Yes", "No", or "Do not know". The total score ranges from -4 to 13 , and a reaction is considered definite when the score is $\geq 9$, probable if $5-8$, possible if $1-4$, and doubtful if $\leq 0$. In this case, the causality of the association between valproate and hypothyroidism was estimated as being "Probable" based on the total score of 8 . We did not re-administer valproate or perform a placebo challenge; therefore, we answered "Do not know" for two of the 10 questions. Our case showed fatigue, but no other symptoms of hypothyroidism, such as weight gain or myxedema; this may have been due to the mild decline in thyroid hormone levels.

Valproate-induced hypothyroidism has been considered to be asymptomatic, even if it occurs [2, 3]. To our knowledge, this is the second report of a case of symptomatic valproate-induced hypothyroidism. Similar to our case, Rao et al. reported a case of bipolar disorder who presented with excessive fatigue under treatment with valproate [5]. While their report noted that symptomatic hypothyroidism can be caused by valproate, whether this can be improved by discontinuation of valproate has remained unclear, because their report did not include a description about the treatment for hypothyroidism. Our case firstly demonstrates that valproate-induced hypothyroidism can be rapidly improved by discontinuation of valproate, even if it is symptomatic.

Clinical manifestations of hypothyroidism such as fatigue and psychomotor retardation are similar to those of depression. Therefore, hypothyroidism that develops during the course of treatment for depression is often overlooked. In such cases, patients can be considered as having treatment-resistant depression [6]. In patients with bipolar disorder who develop treatment-resistant depressive episodes, mood stabilizers such as valproate and lithium are continued, and patients are often supplemented with other treatments. Thyroid function is regularly screened for lithium, but is less likely to be tracked in patients using valproate [7]. Although the incidence of hypothyroidism due to valproate is speculated to be low, our case suggests that valproate-induced hypothyroidism should be considered when patients complain of excessive fatigue under treatment with valproate.

The mechanism of valproate-induced hypothyroidism is unclear. In our case, F-T4 was decreased, but TSH did not increase in reactivity, suggesting central hypothyroidism. Central hypothyroidism is caused by a malfunction of the hypothalamic-pituitary-thyroid (HPT) axis. Previous studies have suggested that $\gamma$-aminobutyric acid (GABA), whose action is enhanced by valproate, affects the HPT axis [8]. Given this finding, the central hypothyroidism in the present case might have been caused by the enhancing effect of valproate on the action of GABA. On the other hand, another mechanism in children using valproate has also been previously reported. Secondary deficiency of zinc and selenium due to valproate may decrease the synthesis of thyroid hormone and cause hypothyroidism with elevated TSH $[9,10]$. However, in adults with bipolar disorder, the mechanism of valproateinduced hypothyroidism has been poorly studied. The effects of valproate on thyroid function have important implications for the treatment of bipolar disorder, so the elucidation of this mechanism is needed in future studies.

\section{Conclusion}

We reported the second case of symptomatic valproateinduced hypothyroidism. Our case suggests that valproate-induced hypothyroidism can be rapidly improved by discontinuation of valproate, even if it is symptomatic. Valproate-induced hypothyroidism should be considered when patients complain of excessive fatigue under treatment with valproate. 


\section{Abbreviations}

F-T4: Free thyroxine; F-T3: Free triiodothyronine; TSH: Thyroid-stimulating hormone; HPT: Hypothalamic-pituitary-thyroid; GABA: $\gamma$-Aminobutyric acid.

\section{Acknowledgements}

Not applicable

\section{Authors' contributions}

TK and HK were involved in patient care and treatment. TK and TS both mainly wrote the manuscript. $Y K, K Y$, and MU interpreted the patient data and were involved in revisions to the manuscript. All authors read and approved the final mauscript.

\section{Availability of data and materials}

Not applicable.

\section{Ethics approval and consent to participate}

Not applicable.

\section{Consent for publication}

We have obtained written consent from the patient for the publication of this case report.

\section{Competing interests}

All authors report no conflicts of interest or financial disclosures related to this manuscript.

\section{Author details}

1 Department of Psychiatry, Nihon University School of Medicine, 30-1 Oyaguchi-Kamicho, Itabashi-ku, Tokyo 173-8610, Japan. ${ }^{2}$ Kunpukai Yamada Hospital, Tokyo, Japan. ${ }^{3}$ Tokyoadachi Hospital, Tokyo, Japan.

Received: 30 May 2020 Accepted: 27 August 2020

Published online: 05 September 2020

\section{References}

1. Rej S, Herrmann N, Gruneir A, Jandoc R, McArthur E, Dixon S, et al. Blood lithium monitoring practices in a population-based sample of older adults. J Clin Psychiatry. 2018. https://doi.org/10.4088/JCP.17m12095.

2. Olcay G, Ahmet KÖ, Fatih T. The effect of antiepileptic drugs on thyroid hormonal function: valproic acid and phenobarbital. Acta Neurol Belg. 2020;120:615-9.

3. Mikati MA, Tarabay H, Khalil A, Rahi AC, El Banna D, Najjar S. Risk factors for development of subclinical hypothyroidism during valproic acid therapy. J Pediatr. 2007;151:178-81.

4. Naranjo CA, Busto U, Sellers EM, Sandor P, Ruiz I, Roberts EA, et al. A method for estimating the probability of adverse drug reactions. Clin Pharmacol Ther. 1981;30:239-45.

5. Pallavi R, Shanker MN, Madhu MG, Bashir A. Valproate-induced subclinical hypothyroidism. J Neuropsychiatry Clin Neurosci. 2008;20:111-2.

6. Bruce MC, Barbara RS, Alexander V. Antidepressant-resistant depression in patients with comorbid subclinical hypothyroidism or high-normal TSH levels. Am J Psychiatry. 2018;175:598-604.

7. Joseph FH, Louise M, Kate W, John RG, Michael K, David PJO. Adverse renal, endocrine, hepatic, and metabolic events during maintenance mood stabilizer treatment for bipolar disorder: a population-based cohort study. PLoS Med. 2016;13:e1002058.

8. Elias AN, Valenta LJ, Szekeres AV, Grossman M. Effect of di-N-propylacetic Acid (Valproic Acid) on the TSH Response to TRH-a presumptive role for gamma aminobutyric acid. Metabolism. 1981;30:1021-3.

9. Bucci I, Napolitano G, Giuliani C, Lio S, Minnucci A, Di Giacomo F, et al. Zinc sulfate supplementation improves thyroid function in hypozincemic down children. Biol Trace Elem Res. 1999;67:257-68.

10. Pizzulli A, Ranjbar A. Selenium deficiency and hypothyroidism: a new etiology in the differential diagnosis of hypothyroidism in children. Biol Trace Elem Res. 2000;77:199-208.

\section{Publisher's Note}

Springer Nature remains neutral with regard to jurisdictional claims in published maps and institutional affiliations.
Ready to submit your research? Choose BMC and benefit from:

- fast, convenient online submission

- thorough peer review by experienced researchers in your field

- rapid publication on acceptance

- support for research data, including large and complex data types

- gold Open Access which fosters wider collaboration and increased citations

- maximum visibility for your research: over $100 \mathrm{M}$ website views per year

At BMC, research is always in progress.

Learn more biomedcentral.com/submissions 